\title{
EL MAESTRO BARTOLOMÉ EN LA CATEDRAL DE SIGÜENZA. UNA HIPÓTESIS EN RELACIÓN AL RETABLO DE SAN MARCOS Y SANTA CATALINA*
}

\author{
F. JAVIER RAMOS GÓMEZ ${ }^{1}$ \\ Investigador independiente
}

\begin{abstract}
El Maestro Bartolomé es uno de los más característicos representantes en Castilla de la llamada pintura hispanoflamenca. En este artículo se propone, por motivos estilísticos, la hipótesis de una intervención parcial del Maestro Bartolomé en el retablo de San Marcos y Santa Catalina de la catedral de Sigüenza, en relación también a una cita documental que sitúa a un pintor llamado Bartolomé en la villa soriana de Almazán en 1504. En algunas figuras del citado retablo se aprecia su característico estilo pictórico, bien conocido gracias a las últimas publicaciones referidas a sus colaboraciones con Fernando Gallego.
\end{abstract}

Palabras clave: Maestro Bartolomé; pintura hispanoflamenca; Sigüenza; Almazán; san Marcos; santa Catalina.

\section{MAESTRO BARTOLOMÉ IN THE CATHEDRAL OF SIGÜENZA. A HYPOTHESIS ON THE ALTARPIECE OF SAINTS MARK AND CATHERINE}

Maestro Bartolomé is one of the most representative masters of Hispano-Flemish painting in Castile. This article examines the stylistic features of the altarpiece of Saint Mark and Saint Catherine (Cathedral of Sigüenza) to suggest the involvement of Maestro Bartolomé in its completion. Documentary evidence reveals a painter named Bartolomé living in Almazán (Soria) in 1504. The technical and formal characteristics of his style are well understood thanks to recent publications on maestro Bartolomé's collaboration with Fernando Gallego.

Key words: Maestro Bartolomé; Hispano-Flemish painting; Sigüenza; Almazán; Saint Mark; Saint Catherine.

Cómo citar este artículo / Citation: Ramos Gómez, F. Javier (2021) "El maestro Bartolomé en la catedral de Sigüenza. Una hipótesis en relación al retablo de San Marcos y Santa Catalina”. En: Archivo Español de Arte, vol. 94, núm. 374, Madrid, pp. 101-116. https://doi.org/10.3989/aearte.2021.06

La figura del Maestro Bartolomé (ca. 1480 - ¿1504?) se ha ido definiendo con unos perfiles cada vez más claros en los últimos años, en comparación y contraste con la obra de Fernando Gallego y de su taller. La correcta comprensión y valoración de su personalidad artística es un tema medular para ir completando el complejo panorama de la pintura hispanoflamenca castellana. Desde la intuición de grand connaisseur de Gudiol Ricart, pasando por las acertadas observaciones de Yarza, Silva Maroto, Anderson y Dotseth ${ }^{2}$, hasta los más recientes estudios radiográficos y reflectológicos realizados en el Kimbell Art Museum of Fort Worth y en el Instituto del Patrimo-

\footnotetext{
* In Memoriam del Dr. José Rogelio Buendía Muñoz, director de mi Tesis Doctoral

1 fjavierramos10@yahoo.com / ORCID iD: https://orcid.org/0000-0001-7292-6572

2 Gudiol Ricart, 1955: 334-336; Silva Maroto, 2004: 262-286, 291-333. Yarza Luaces, 2006: 15-60. Dotseth / Anderson / Roglán, 2008: 73-146.
} 


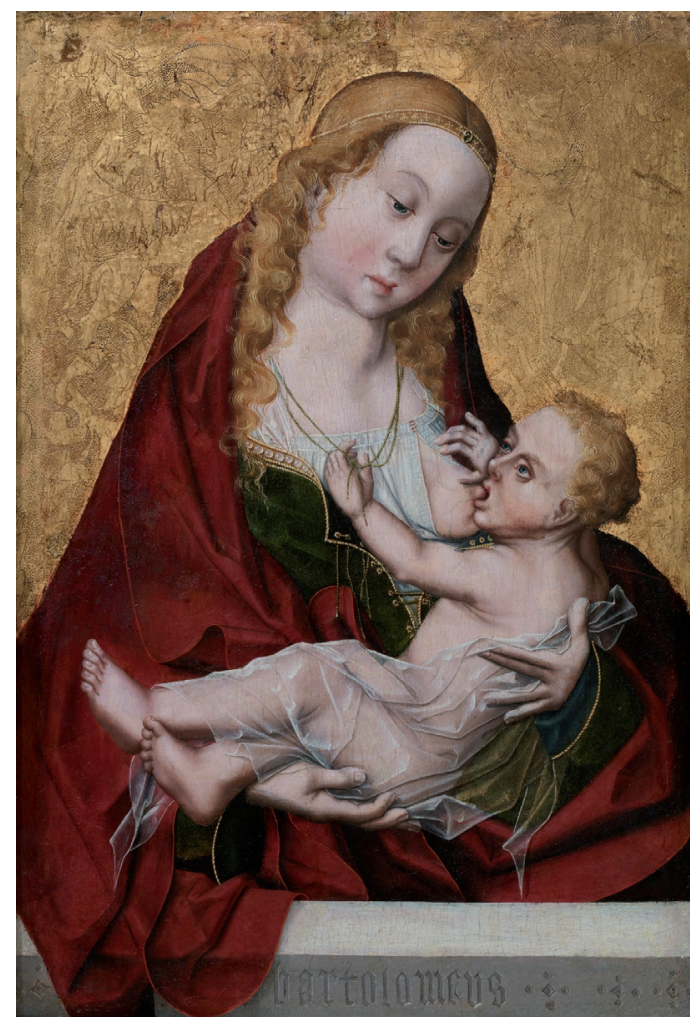

Fig. 1. Maestro Bartolomé (act. 1480 - ¿1504?). Virgen de la leche, c. 1490. Madrid: Museo Nacional del Prado (Foto Museo Nacional del Prado). nio Cultural Español (IPCE), la obra atribuida a este pintor se ha reconstruido por comparación con su único cuadro firmado, la Virgen de la Leche del Museo del Prado [fig. 1] $]^{3}$. Se ha deducido su participación en los retablos mayores de la catedral de Ciudad Rodrigo (Salamanca) ${ }^{4}$ - conservado parcialmente en el University of Arizona Art Museum - y de Santa María la Mayor de Trujillo (Cáceres) ${ }^{5}$. La actividad de Bartolomé en ambos retablos parece ya fuera de duda, pues ha sido aceptada y defendida con argumentos estilísticos, dibujísticos, técnicos e iconográficos muy sólidos y coincidentes por Yarza Luaces, Silva Maroto, Anderson, Dotseth y Sanz Fernández.

Bartolomé debió nacer antes de 1455, pues en 1480 ya era un pintor perfectamente formado y capaz de acometer empresas importantes, aunque hay poca información sobre ello debido a la escasez de documentos del siglo XV en Casti$11 a^{6}$. En este sentido ha sido importante la publicación de las Actas Capitulares de la catedral de Salamanca, en las cuales se cita a "Bartolomé pintor, vecino de Salamanca", quien renuncia a una casa pequeña sin sobrado que tenía arrendada al cabildo salmantino en julio $1482^{7}$. De referirse al Maestro Bartolomé, lo que parece muy probable, sería la primera cita documental publicada del Maestro Bartolomé, y le situaría

\footnotetext{
${ }^{3}$ Existe otra versión muy similar atribuida a Fernando Gallego en una colección privada madrileña. Alba / García Maíquez / Gayo et al, 2014: 125-26. Se intuye que las dos versiones pudieron pintarse al unísono inspirándose en un mismo modelo, probablemente basado en alguna versión invertida de la Virgen con el Niño de Robert Campin (Städel Museum, Fráncfort).

${ }^{4}$ Se conocen bastante bien su cronología (1480-1488), su historia material, su periplo por distintas colecciones anglosajonas, así como sus fuentes de inspiración, dibujo subyacente y las diversas manos que participaron en él, dirigidas por los dos maestros que se repartieron sus tablas: Fernando Gallego y Bartolomé. No es necesario repetir la bibliografía pues ya está recopilada en: Silva Maroto, 2004: 64-65 y 241-264. Los estudios posteriores más destacados sobre el retablo de Ciudad Rodrigo son: Yarza Luaces, 2006; Dotseth / Anderson / Roglán 2008.

${ }^{5}$ Silva Maroto, 2004: 291-333: atribuye a Bartolomé el segundo cuerpo del retablo: Visitación, Natividad, Epifanía, Presentación en el templo, san Marcos y san Lucas. Anderson, 2008: 74: le atribuye la Visitación, Epifanía, Presentación en el Templo, San Lucas, San Marcos (solo el león), uno de los apóstoles de la Oración en el Huerto y otros detalles; en el retablo de San Ildefonso (Zamora, catedral) le asigna la figura femenina de la Adoración de las reliquias. Hay una investigación posterior de Sanz Fernández, muy extensa y pormenorizada en relación al contexto local del retablo, que asigna a Bartolomé las cuatro escenas del segundo cuerpo y otras dos tablas en colaboración con Fernando Gallego. Sanz Fernández, 2009: 46. El retablo de Trujillo ha sido restaurado por el IPCE, cuyos técnicos han dado a conocer sus conclusiones que coinciden con las de Sanz Fernández, Anderson y Silva Maroto. Otros autores anteriores, con menos información técnica, adelantaron la cronología a 1480 (Gaya Nuño, 1958: 20-21; García Sebastián, 1979: 19; Azcárate Ristori, 1996: 386) o incluso a 1475-1480 con argumentos poco sólidos (Ramos Rubio, 2009: 65 y 71; Gudiol Ricart, 1955: 324).

${ }^{6}$ Silva Maroto, 2004: 423. Esta autora lamenta la falta de datos documentales y hace hincapié en lo poco que se conoce sobre su vida y obra. Yarza Luaces, 2006: 24.

7 Vicente Baz, 2008: 437-438: <https://catedralsalamanca.org/wp-content/uploads/ActasCapitulares.pdf> [Consultado el 7-XII-2020]. Esta noticia nos sitúa con seguridad a Bartolomé en relación con el cabildo salmantino, lo que es muy importante, pues hasta ahora solo conocíamos su nombre a través de la inscripción de la Virgen de la Leche del Museo del Prado, cuya procedencia desconocemos.
} 
abandonando una casa del cabildo en Salamanca en el momento en que se fecha el inicio del retablo de Ciudad Rodrigo. En este documento se cita al pintor tal y como se le nombra en el documento seguntino de 1504, es decir, por el nombre de pila, el oficio y el lugar de residencia.

A caballo entre los siglos XV y XVI existieron en los reinos peninsulares otros pintores llamados Bartolomé, que conviene repasar para abrir posibles vías de investigación y cerrar otras. Además de Bartolomé Bermejo, el primero que encontramos es Bartolomé González, documentado en Palencia entre 1453 y 1479, quizás el mismo pintor de este nombre documentado en Salamanca en $1456^{8}$, pero nada se conoce de sus obras, por lo que no es posible pronunciarse sobre la posibilidad de que pudiera ser Maestro Bartolomé. Poco se sabe también de un Bartolomé Sánchez que vivía en Salamanca en 14719. Existió después también en Palencia un Bartolomé de Castro, seguidor de segunda fila de Pedro Berruguete a principios del siglo XVI ${ }^{10}$. En Valladolid se documenta entre 1505 y 1507 a Bartolomé de Villasante, pero no se conoce ninguna pintura de su mano ${ }^{11}$ y no sabemos nada de él antes ni después de esas fechas. No podemos descartar que sea el Maestro Bartolomé, aunque no lo creemos probable. En Ávila encontramos a Bartolomé de Santa Cruz, un pintor imbuido de italianismo que murió muy probablemente en $1507^{12}$ y que nada tiene que ver con el estilo del Maestro Bartolomé. Hubo también un colaborador de Bermejo, de Miguel Ximénez y de Martín Bernat en las puertas del retablo de la Seo de Zaragoza llamado Bartolomé Vallés, con quien Post lo intentó asimilar, pero su estilo no coincide ${ }^{13}$.

Es curioso que con esta cantidad de pintores homónimos, el Maestro Bartolomé no utilizase su apellido, quizá deseara, por alguna razón, no manifestarlo ${ }^{14}$. Aun así, no era extraño en la época que se citara a pintores y entalladores únicamente por su nombre de pila.

\section{Maestro de las Armaduras o de los Rostros Siniestros: "Bartolomeus"}

Cuando la Virgen de la Leche fue adquirida por el Museo del Prado en 1926, la firma de "Bartolomeus" se relacionó con Bartolomé Bermejo, aunque poco después se corrigió el error ${ }^{15}$. El primero que señaló la relación entre esta Virgen de la Leche y algunas escenas del retablo de Ciudad Rodrigo fue Gudiol, aunque Angulo ya había apuntado su vinculación con un seguidor de Fernando Gallego. Otros autores desecharon la idea a causa del mal estado de conservación y de los repintes del altar de Ciudad Rodrigo ${ }^{16}$. Este colaborador de Fernando Gallego había sido de-

\footnotetext{
${ }^{8}$ Silva Maroto, 1990: tomo I, 146-147. Vicente Baz, 2008: 349. <https:/catedralsalamanca.org/wp-content/ uploads/ ActasCapitulares.pdf> [Consultado el 7-XII-2020].

9 Vicente Baz, 2008: 388.

${ }^{10}$ Silva Maroto, 1992: 437-452. Mateo Gómez, 2002: 199-224. Bartolomé de Castro también firma dos de sus obras en letra gótica, un San Onofre y un Santo Domingo, pero utilizando su inicial y su apellido.

${ }^{11}$ Bartolomé de Villasante contrató un retablo con Catalina Alonso de Santisteban en la iglesia del Salvador de Valladolid (1505). En 1507 el retablo estaba todavía sin terminar y Villasante había salido de Valladolid. Redondo Cantera, $2004: 373$.

${ }^{12}$ Irune Fiz Fuertes ha propuesto la asimilación entre el Bartolomé de Santa Cruz que colabora con Gil de Encinas en el retablo de Horcajo de las Torres (Ávila) y el Santa Cruz que trabaja en el retablo mayor de la catedral de Ávila después de Berruguete y antes de Juan de Borgoña. Fiz Fuertes, 2013: 62-68.

${ }^{13}$ La relación con Bartolomé Vallés (en Zaragoza en 1482) ha sido criticada: Torné Poyatos, 1987: 64. Lo último publicado en relación a este maestro: Ibáñez Fernández, 2018: 58 y 95.

${ }^{14}$ Cómez Ramos, 2005: 707-724. Plantea la interesante hipótesis del posible origen judío de algunos artistas. Véase también: Marías Franco, 2016: 425-447. Bartolomé de Cárdenas firmaba sus obras como Bartolomé Bermejo o Rubeus.

${ }^{15}$ La obra fue adquirida por 20.000 pesetas a propuesta del Patronato del Tesoro Artístico Nacional como obra de Bermejo, por Real Orden publicada en: Gaceta de Madrid, 26 de diciembre de 1926, n. ${ }^{\circ}$ 360, p. 1703. Se adquirió tras ser denegado su permiso de exportación. Se conserva también la carta por la que se comunica la recogida del cuadro en la residencia de su propietario, el conde de las Almenas: Carta, 22 abril de 1927, Archivo del Museo Nacional del Prado, Madrid, Caja $107 /{ }^{\circ}{ }^{\circ}$ Exp. 1. La bibliografía sobre esta tabla aparece recogida en: <www.museodelprado.es/coleccion/obra-de-arte/lavirgen-de-la-leche/06a0c7a4-a6a1-40c4-b677-9773bf813681> [consultado el 31-V-2020]. La obra ha sido sometida a dos restauraciones, una en 1951 llevada a cabo por Enrique Alarcón Cabrera, y otra en 2010 a cargo de Ma Antonia López Asiaín.

${ }^{16}$ Gudiol Ricart, 1955: 334 (es curioso que Gudiol no citase la intervención del Maestro Bartolomé en el retablo de Santa María de Trujillo). Gaya Nuño, 1958: 29: la hipótesis de Gudiol le parece poco respaldada por los datos. Quinn,
} 


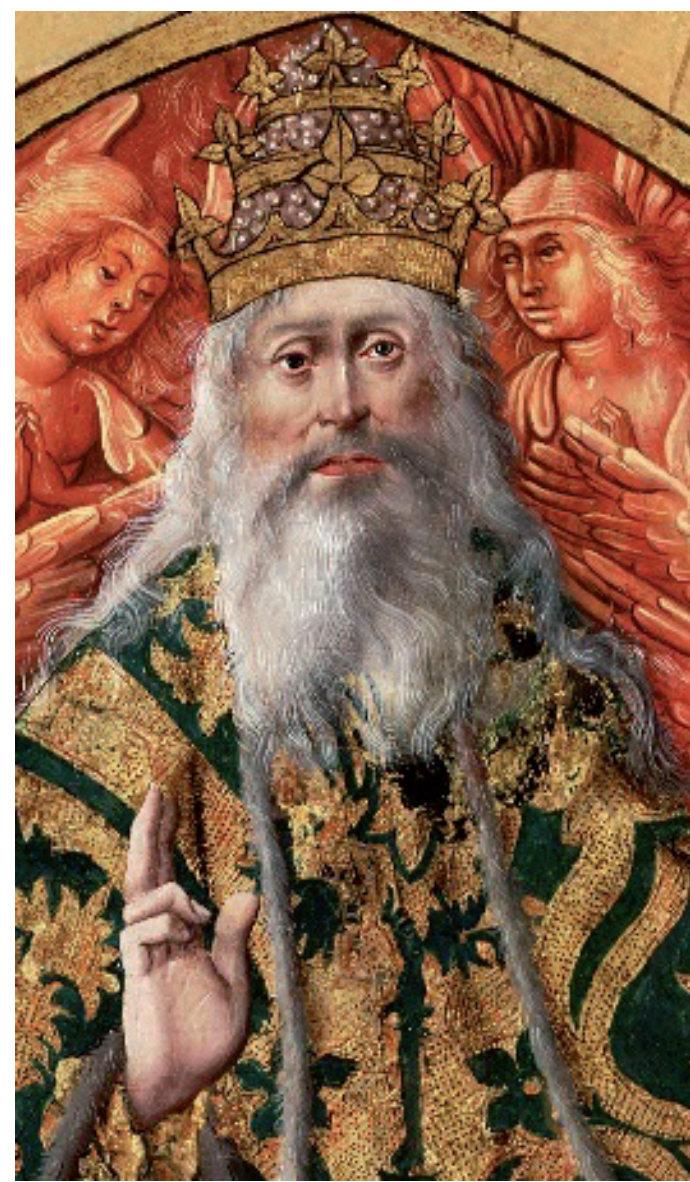

Fig. 2. Atribuido a Maestro Bartolomé. Caos (detalle), ¿Después 1493? Tucson (Arizona): University of Arizona Art Museum. nominado Maestro de las Armaduras en 1908 por Bertaux y después Maestro de los Rostros Siniestros por Gaya Nuño ${ }^{17}$. Joaquín Yarza, a quien siguió después Silva Maroto, restableció con argumentos formales muy sólidos la identificación entre el "Bartolomeus" que firmó la Virgen de la Leche y el Maestro de las Armaduras, concretando las sugerencias de Angulo y Gudiol ${ }^{18}$.

Exceptuando la Virgen de la Leche y los paneles que se le atribuyen de los retablos de Ciudad Rodrigo y de Trujillo, no se han dado a conocer más obras de este pintor ${ }^{19}$. Aunque se le cita en las Actas del Cabildo ${ }^{20}$ salmantino de 1482, y según aquí proponemos, también en Almazán, no hemos podido localizar su nombre en otros documentos publicados sobre artistas castellanos de finales del XV y principios del $\mathrm{XVI}^{21}$.

La restauración y los estudios técnicos llevados a cabo en los retablos de Ciudad Rodrigo y de Trujillo han confirmado estas atribuciones $^{22}$. Barbara Anderson ha descrito en detalle las características del estilo de Bartolomé; entre ellas, destacan la elección de tipos humanos característicos que repite una y otra vez, el uso de una indumentaria rica en detalles y el empleo de figuras envueltas en amplios mantos plegados sobre cuerpos de hombros es-

1961: 30: le resulta difícil ratificar la hipótesis de Gudiol, si bien reconoce la clara relación entre algunas figuras femeninas del retablo de Ciudad Rodrigo y la Virgen de la Leche. Camón Aznar (1978) y García Sebastián (1979) guardaron silencio al respecto. Torné Poyatos, 1987: 67: mantuvo la opinión de Angulo. Pérez Sánchez, 1996: 27: considera a Bartolomé un colaborador directo de Fernando Gallego.

${ }_{17}$ Gaya Nuño, 1958: 22-23. Básicamente, las tablas de Ciudad Rodrigo que se atribuyen a Bartolomé son las siguientes: Caos, Creación de Eva, Jesús entre los doctores, Tentaciones de Cristo, Entrada en Jerusalén, Transfiguración, Camino del Calvario, Crucifixión, Lamentación ante Cristo muerto, Resurrección, Cena en casa de Simón y Última Cena. Algunas de ellas con ciertas dudas por la intervención de ayudantes. En gran medida, estas atribuciones coinciden con las que hizo Quinn a la llamada Mano II de dicho retablo: Quinn, 1961: 30-31.

18 Yarza Luaces, Joaquín (1995). "La pittura spagnola del Medioevo: il mondo del gotico”. En: Pérez Sánchez, Alfonso E. (ed.), La pittura spagnola, I, Milán, p. 183. Tomo esta referencia de: Yarza Luaces, 2001: 213.

${ }_{19}$ Anderson, 2008: 74-81: le atribuye una pequeña intervención en una figura femenina de la Adoración de las reliquias de san Ildefonso, del retablo de San Ildefonso (Zamora, catedral), y posiblemente el Descenso de Cristo al Limbo (Museo de Bellas Artes de Asturias).

${ }^{20}$ Vicente Baz 2008; Vicente Baz 2016. Se hallan extractados los Libros de Actas del Cabildo de la catedral de Salamanca desde 1298 hasta 1506.

${ }^{21}$ Entre la ingente bibliografía sobre el asunto, citaré a modo de ejemplo: Zarco del Valle, 1916. Marqués de Saltillo, 1948. Collar de Cáceres, 1989. Silva Maroto, 1990; 1996: 163-179. Redondo Cantera, 2002: 175-186. Ramos Rubio 2009. Fiz Fuertes 2010: 91-102; 2014: 157-171; 2015: 407-439; 2018: 537-556. Vicente Baz, 2016: $<$ https://catedralsalamanca.org/wp-content/uploads /ActasCapitulares-2.pdf> [consultado el 6-XII-2020].

${ }^{22}$ Yarza Luaces, 2001: 213; 2006: 21: lo aseguró y luego se ratificó. Silva Maroto, 2004: 262. Sobre los estudios físicos, químicos y del dibujo subyacente llevados a cabo en el retablo de Trujillo, véase: Gómez / Jover de Celis, 2008: 49-60. Antelo / Gabaldón / Vega, 2008a: 61-73. Antelo / Gabaldón / Vega, 2008b: 75-88. Sobre las restauraciones y los estudios técnicos del antiguo retablo de Ciudad Rodrigo: Barry, 2008: 147-226. 


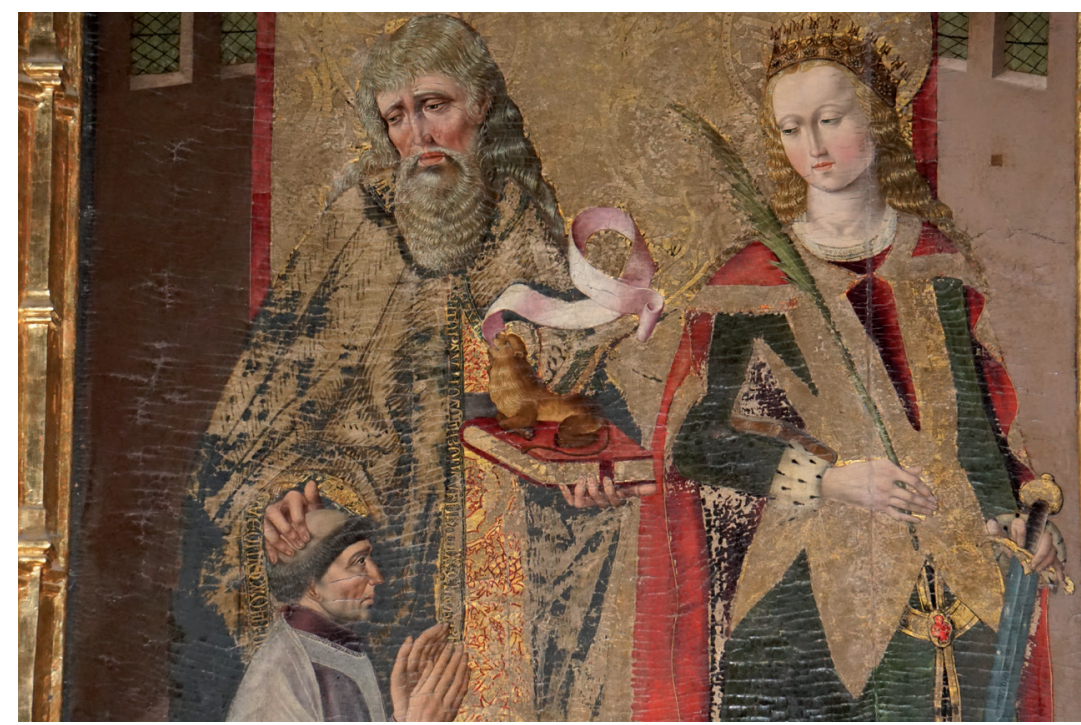

Fig. 3. Atribuido a Maestro Bartolomé. San Marcos y Santa Catalina con don Juan Ruiz de Pelegrina (detalle), c. 1500-1504. Catedral de Sigüenza (Guadalajara): Capilla de San Marcos.

trechos — que tienden a la forma triangular-. Sus rostros suelen tener cejas arqueadas sobre ojos hundidos para aumentar la expresión de tristeza y unos pómulos muy marcados que son como su rúbrica personal ${ }^{23}$.

Sus figuras humanas han sido clasificadas en tres tipologías principales que repite incesantemente. El primer tipo representa a niños, ángeles y muchachos jóvenes con un amplio rango de variantes. El segundo tipo aparece en hombres de avanzada edad, de prominentes pómulos cincelados sobre huecas mejillas y con barba gris recortada o larga, como en el Dios Padre de la tabla del Caos [fig. 2]. Este modelo se repite en el rostro de San Marcos [fig. 3] del retablo que aquí se estudia, con la lógica evolución producida por el tiempo. El tercero es utilizado para hombres jóvenes, barbados y melancólicos, con las cejas arqueadas, y suele representar a Cristo ${ }^{24}$. También se aprecia una expresividad que roza a veces lo grotesco, con elementos anatómicos incoherentes. Además, Bartolomé destaca por la continua, variada y compleja referencia a modelos alemanes de finales del siglo XV, ya sean estampas, libros o pinturas. Sanz Fernández llegó a conclusiones similares al estudiar el retablo de Trujillo, donde reconoce el estilo de Bartolomé25.

\section{El retablo de San Marcos y Santa Catalina. Bartolomé en Sigüenza y Almazán}

La hipótesis que proponemos sobre la intervención de Bartolomé en este retablo se basa en el reconocimiento formal de que el estilo del autor principal del retablo de San Marcos y Santa Catalina coincide con la obra conocida de Bartolomé. En segundo lugar, existe un documento del Libro de cuentas de la parroquia de Hijes que nombra en 1504 a un Bartolomé pintor, vecino de

${ }^{23}$ Anderson, 2008: 73-84.

${ }^{24}$ Silva Maroto, 2004: 281-282. Anderson, 2008: 74-82. Los paisajes, con tonalidades azuladas al fondo, también son característicos en las obras de Bartolomé, así como la manera de hacer los árboles del fondo y algunos detalles en los ropajes.

${ }_{25}^{25}$ Sanz Fernández, 2009: 139-141: Bartolomé muestra inclinaciones expresivas alemanas, se inspira en estampas y armaduras también germanas, mantiene la tradición del gótico internacional salmantino, usa muchos de los convencionalismos de Fernando Gallego (desproporción en el tamaño de sus figuras de primer plano, carácter expresivo de las manos de sus personajes, claridad y precisión en sus dibujos subyacentes) y sobre todo se reconoce por sus inconfundibles rostros de Cristo y María. 
Almazán, que situaría a nuestro pintor en el obispado de Sigüenza. Analizaremos primero el documento y después la posible intervención de Bartolomé en este retablo de la catedral seguntina.

El documento en cuestión es una recomendación del visitador obispal don Ignacio de Collantes $^{26}$, que fue provisor durante el episcopado de don Bernardino López de Carvajal (1495-1512), para que la iglesia de Hijes contratase urgentemente un retablo mayor con artistas de acreditada solvencia, citándose al entallador Íñigo de Riaza y a los pintores Bartolomé, Frutos Flores ${ }^{27}$ y Hernando Rincón: "Iten mandamos [...] se faga dentro de dos años primeros siguientes a lo menos, la talla de un gentil retablo [...] e la pintura faga cualquiera, Bartolomé, pintor de Almazán, o Frutos o Rincón, vezinos de Guadalajara"28.

Sabemos que el retablo de Hijes fue pintado finalmente por Francisco de la Nestosa entre 1510 y $1517^{29}$. El hecho de que se cite a Bartolomé en compañía de un artista tan valorado como Rincón $^{30}$ significa que el cabildo le reconocía y que valoraba su capacidad.

En este contexto, hay otro documento de las Actas Capitulares de la catedral de Sigüenza, ya conocido, que podría referirse también a Bartolomés1. En él se habla de un pintor de Almazán que cobra junto a Francisco de la Nestosa la policromía de dos imágenes de la Virgen y San Ildefonso en 1499. Dado que no se ha constatado la presencia de ningún otro pintor en Almazán, es plausible que se refiera a Bartolomé, cinco años antes del documento de Hijes ${ }^{32}$. La hipótesis de la presencia de Bartolomé en Sigüenza y Almazán es consistente con el hecho de que su nombre no haya aparecido entre los documentos conocidos de esos años en el área salmantina, además, la manera de citar al pintor coincide en ambos casos, como ya hemos señalado.

La historia del retablo de San Marcos y santa Catalina es bastante sencilla, pues prácticamente no ha salido de la catedral de Sigüenza ${ }^{33}$. El fundador de esta capilla funeraria fue don Juan Ruiz de Pelegrina, quien la dotó con 18.000 maravedíes anuales de renta antes de morir en Burgos en 1497. Fue protonotario, chantre en la catedral de Sigüenza y maestrescuela de Burgos ${ }^{34}$. Sus testamentarios fueron sus sobrinos Juan de Vallejo y Juan López de Pelegrina, canónigo y racionero

${ }^{26}$ Yáñez Neira, 1986: 385-398. Ignacio de Collantes nació en Hita en fecha desconocida, era doctor en Decretos y Cánones y se involucró en la reforma del monasterio cisterciense de Ovila (Guadalajara), del que fue abad comendatario. Luego profesó en la orden y llegó a ser abad de Valbuena y de Santa María de Huerta (donde murió en 1539). Fue reformador del Císter castellano y mando supremo de la congregación desde 1522. Apareció en Sigüenza como clérigo en 1494 y gracias a su sólida formación y a contar con la confianza de don Bernardino López de Carvajal desarrolló las importantes tareas de visitador y provisor de la diócesis. Desarrolló con gran celo estas labores, tanto en el plano material como en el espiritual, lo que produjo algún conflicto con el cabildo. Parece que tuvo gran interés por la pintura y especial gusto por Juan Soreda.

${ }^{27}$ Frutos es un misterioso pintor, afincado en Guadalajara y sin obra conservada, aparece junto a Juan de Borgoña, Francisco de Amberes, Francisco Guillén, Andrés Segura y Hernando Rincón en la policromía del banco del retablo mayor de la catedral de Toledo (1500-1503), y curiosamente es él quien más cobra. Pérez Sedano, 1914: 24-28. La policromía del retablo estaba ya terminada y pagada en 1504: Gómez Espinosa, 2001: 573-582.

${ }^{28}$ Libro $1^{\circ}$ de Cuentas de Hijes, 1504, Archivo Histórico Diocesano de Sigüenza, Sigüenza (AHDS), fol. 28v. Publicado completo en: Marco Martínez, 1997: 31.

${ }^{29}$ Francisco de la Nestosa también realizó los retablos de Sienes, El Atance y diversas obras en la catedral seguntina (1498-1518). Ninguna de estas obras se ha conservado. Ramos Gómez, 2004: 66-71.

${ }^{30}$ Ramos Gómez, 1998: 80-86 y 228. Hernando Rincón tenía ya una larga trayectoria en Zaragoza, Valladolid, Toledo, Guadalajara y Soria: su obra más importante fue el desaparecido retablo de Santa María de Medinaceli. Romero Medina, 2009: 35-62. Rincón fue recomendado por el visitador obispal para el retablo de Sienes en 1506, junto a Juan Soreda y Frutos Flores.

31 Muñoz Párraga, 1987: 381.

${ }^{32}$ En esos años hubo mucho trabajo pictórico en el obispado de Sigüenza. Se documentan retablos en Sienes, Hijes, El Atance, Anguita, Medinaceli, Almazán, Atienza, El Muyo, Turmiel, Zaorejas y dos en la colegiata de Berlanga de Duero. La competencia era fuerte, además de Bartolomé, pululaban por el obispado de Sigüenza pintores como Sancho de Contreras, Juan de Segovia, Sancho de Zamora, Francisco de la Nestosa, Frutos Flores, Rincón de Figueroa y Juan Soreda.

33 Únicamente se constatan dos salidas. Una fue a la Exposición Internacional de Barcelona de 1929. Gómez Moreno, 1929: 261. La segunda, para su restauración en los años noventa en la Facultad de Bellas Artes (Madrid, Universidad Complutense) llevada a cabo por Teresa Escohotado Ibor.

${ }^{34}$ Véase la interesante interpretación sobre el sentido de su escudo en relación con el cardenal veneciano Marco Barbo, en: Olea Álvarez, 2016: 88-89. 
de Sigüenza respectivamente, quienes encargaron el retablo y según la inscripción, la obra de la capilla estaba terminada en $1511^{35}$.

Respecto a la autoría del retablo hay disparidad de opiniones entre los estudiosos. Pérez Villamil dio a conocer el nombre de Antonio Contreras ${ }^{36}$, uniendo equívocamente la firma del espadero "Antonio" que aparece en la espada de Santa Catalina y el nombre del pintor Sancho de Contreras documentado en Sigüenza en $1486^{37}$. Siguiendo esta pista, Post creó la figura del Maestro del Retablo de San Marcos y Santa Catalina, autor que juzga dotado de una gran personalidad. Gudiol señaló la falta de referencias precisas sobre Antonio Contreras; Mayer y Camón Aznar lo incluyeron dentro de la escuela toledana ${ }^{38}$ y recientemente yo mismo desvinculé el retablo de la nómina del inexistente Antonio Contreras ${ }^{39}$.

\section{Análisis estilístico e iconográfico del retablo de San Marcos y Santa Catalina}

La escena central representa a San Marcos y Santa Catalina con don Juan Ruiz de Pelegrina [ver fig. 3]. Apreciamos la autoría de Bartolomé por el rostro de San Marcos, que usa el mismo modelo descrito por Barbara Anderson para el Dios Padre del panel del Caos de Ciudad Rodrigo [ver fig. 2]. El rostro de la santa también remite a modelos de Bartolomé. La manera de modelar las mejillas, con delicados tonos que van del blanco al rosa velado, las cejas de una curvatura constante y el tono rubio del cabello son comparables a la citada Virgen de la Leche [ver fig. 1] y a la protagonista del panel de la Creación de Eva [fig. 4] del UAMA. Múltiples detalles, como la expresividad de las manos, la cenefa de la túnica de Marcos con decoración epigráfica y la representación del pequeño león ${ }^{40}$ que aparece sobre el libro, se relacionan con obras atribuidas a Bartolomé. Las pequeñas variaciones son fruto de la evolución formal de Bartolomé durante los años noventa, que no podemos definir todavía con claridad. Las pérdidas de pintura en la túnica de San Marcos permiten ver el característico dibujo subyacente a base de líneas cortas, gruesas y paralelas del Maestro Bartolomé ${ }^{41}$. Iconográficamente, sigue una tradición de santos dobles que procede del gótico internacional y de la que existieron numerosos retablos en la catedral seguntina, como los realizados por Juan de Sevilla. Ambos santos tenían el don de la elocuencia y vivieron y murieron en Alejandría ${ }^{42}$. Quizá por ello se decidió unirlos en este altar. La representación del fundador de la capilla como donante arrodillado es el único retrato conocido de Bartolomé, pero suficiente para acreditarle como un buen especialista. Es poco habitual el modo en que San Marcos apoya su mano sobre la cabeza tonsurada del donante - gesto que se da también en el Tríptico de la Epifanía de la colegiata de Covarrubias-, acusando una fuerte tensión que demuestra su gran interés y cuidado en la representación de las manos. Esa misma tensión se observa también en las manos de Santa Catalina. Por su posición de perfil y su actitud orante, se aprecia que el cliente

35 Pérez Villamil, 1899: 273. La fase arquitectónica estaba terminada en 1501. Muñoz Párraga, 1987: 285.

${ }^{36}$ Federico, 1954: 40. Azcárate Ristori, 1996: 384. Peces Rata, 1997: 13. Reiteran lo mismo.

${ }_{37}$ Yela Utrilla, 1923: 381. El documento se refiere al retablo no conservado de San Agustín, que fue realizado por Sancho de Contreras. Se trata de un dato interesante que apenas ha tenido eco en la bibliografía. Esta capilla de San Agustín estaba en el hospital seguntino de San Mateo, gestionado por el cabildo catedralicio. Pérez Villamil, 1899: 470: confunde la fecha de este documento, señalando erróneamente 1496 en lugar de 1486. Podemos precisar que en este retablo ya se estaba trabajando en diciembre de 1485: Actas capitulares (1486-1495), 10 de diciembre 1485, Archivo Catedralicio de Sigüenza (ACS), Sigüenza, tomo 10, fol. 21: "Mandaron dar lugar en el ospital para los pintores que pintan el retablo de sant Agustín".

${ }_{38}$ Post, 1933: 458-462. Tormo y Monzó, s.f.: 38. Gudiol Ricart, 1955: 355. Camón Aznar, 1978: 634. Collar de Cáceres, 1989: 40. Algunos autores asignaron obras a Antonio de Contreras a partir de esta atribución dudosa y confusa; Post le atribuyó el retablo de Santa Ana (Berlanga de Duero, colegiata) y otro en la colección Lafora (Madrid).

${ }^{39}$ Recogí la bibliografía del retablo anterior a 2004 en: Ramos Gómez, 2004: 65-66 y 79-83. Planteé la participación de un pintor principal y de un ayudante.

${ }^{40}$ Comparable al león que aparece en la escena de la Creación de Eva (UAMA, Tucson).

${ }^{41}$ Sobre el dibujo preparatorio del Maestro Bartolomé: Barry, 2008: 205-215. Gómez / Jover de Celis, 2008: 54.

42 Silva Maroto, 2004: 158. Santa Catalina también favorecía la buena muerte y era patrona del clero. 


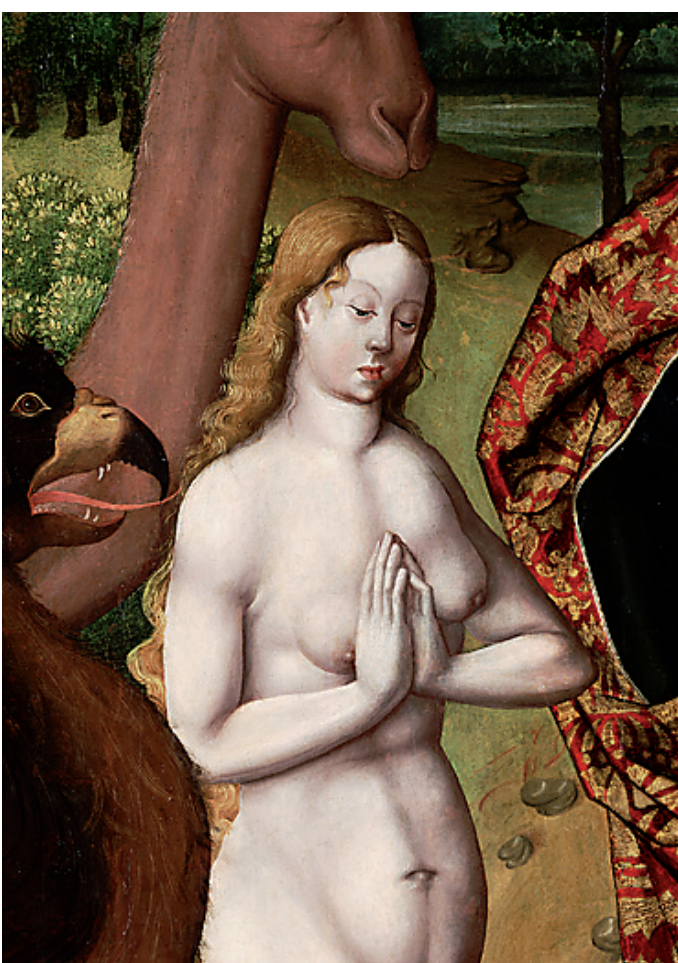

Fig. 4. Atribuido a Maestro Bartolomé. Creación de Eva (detalle), ¿Después 1493? Tucson (Arizona): University of Arizona Art Museum. intentó imitar el retrato del cardenal Mella en el retablo de San Ildefonso (catedral de Zamora) de Fernando Gallego ${ }^{43}$. Juan de Mella había sido obispo de Sigüenza (1465-1467) después de haberlo sido de Zamora. Como colaborador de Fernando Gallego, Bartolomé conocería esta obra.

Antes de analizar individualmente cada una de las escenas narrativas laterales que componen este retablo, me gustaría señalar que la complejidad para conocer su autoría radica en que en dichas escenas se mezclan varias manos y en que los elementos propios de Bartolomé solo se aprecian en aspectos compositivos, en detalles concretos o en figuras aisladas que iremos señalando. Lo cierto es que en estas cuatro escenas narrativas se aprecia la participación de al menos dos manos más, una cercana al Maestro de Sinovas que trabaja en los personajes secundarios de las escenas narrativas y en la zona derecha del bancal; y otra mano más italianizante que trabaja en algunas figuras de la Crucifixión, por ejemplo, en Cristo, y en la zona izquierda del bancal. No obstante, parece que Bartolomé fue el maestro principal, pues realizó la tabla central. Es posible que la ejecución de las escenas laterales fuera total o parcialmente subcontratada a estos dos pintores ${ }^{44}$.

Un ejemplo de todo esto es la Predicación de San Marcos en Alejandría [fig. 5], que muestra un leve desplazamiento lateral del eje visual de la escena, rasgo característico de Bartolomét5. Pero más definitorio de su estilo es el rostro del santo, que mantiene de nuevo la tipología ya descrita de pómulos marcados y mejillas retraídas. Esta figura de perfil es comparable al apóstol con bastón que aparece en primer plano de la Entrada en Jerusalén [fig. 6], al apóstol del centro de la Santa Cena y al personaje a caballo del Calvario del retablo de Ciudad Rodrigo (para estas dos últimas escenas Bartolomé se inspiró en grabados del maestro I.A.M. de Zwolle y de Schongauer respectivamente ${ }^{46}$. El paisaje visto a través del arco es coincidente con los paisajes pintados por Bartolomé en el retablo de Ciudad Rodrigo ${ }^{47}$. La techumbre de madera se utilizó también, por ejemplo, en el Nacimiento de Cristo del retablo de Trujillo, pero además aquí se introduce una nota renacentista en el púlpito. El gusto por los tocados es una constante en la obra de Bartolomé, particularmente en el retablo de Ciudad Rodrigo, donde parece inspirarse en los gorros, sombreros y bonetes grabados en el Liber chronicarum cum figuris ab

43 Obra fechada hacia 1480. Silva Maroto, 2004: 147. Otra semejanza es el capelo de tres borlas depositado en el suelo, signo de su dignidad eclesiástica de protonotario apostólico.

44 Serra, 2010: 18. Esto sucedía cuando un taller no podía atender a la demanda que se le requería.

45 Ese desequilibrio ha sido definido como característica de Bartolomé por Joaquín Yarza, junto a la delicadeza en el uso ocasional de tonos suaves, distorsión de los cuerpos hasta extremos a veces grotescos y fuerte expresionismo. Yarza ha sido quien más ha reivindicado la figura de Bartolomé, y quizá el que mejor haya entendido su fuerte carácter y su flexibilidad a la hora de moverse entre lo caricaturesco y lo delicado. Le considera el más importante colaborador de Fernando Gallego. Yarza Luaces, 2006: 20 y 58-59.

46 Reproducidos ambos en: Dotseth, 2008: 126 y 133. La imitación del grabado se basa en la disposición de las figuras, pero el tipo humano y el fuerte carácter de los rostros de los personajes son creación de Bartolomé.

47 Estudiados en: Dotseth / Anderson / Roglán, 2008: 240. 


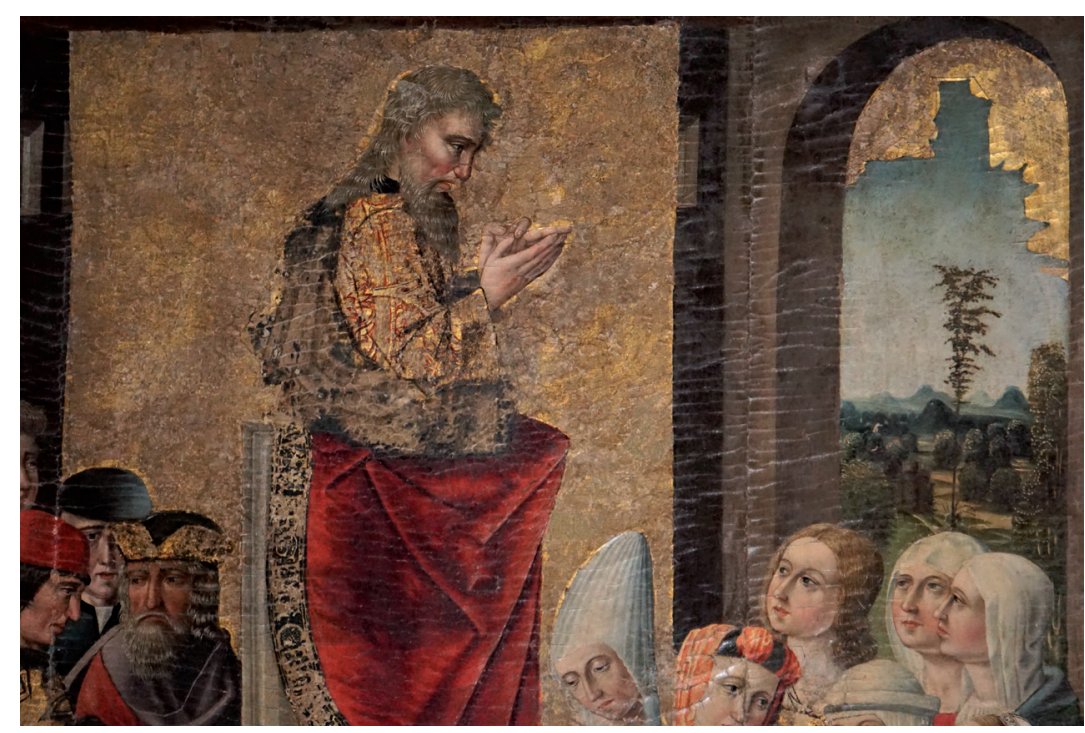

Fig. 5. Atribuido a Maestro Bartolomé y colaboradores. Predicación de San Marcos en Alejandría (detalle), c. 1500-1504. Catedral de Sigüenza (Guadalajara): Capilla de San Marcos.

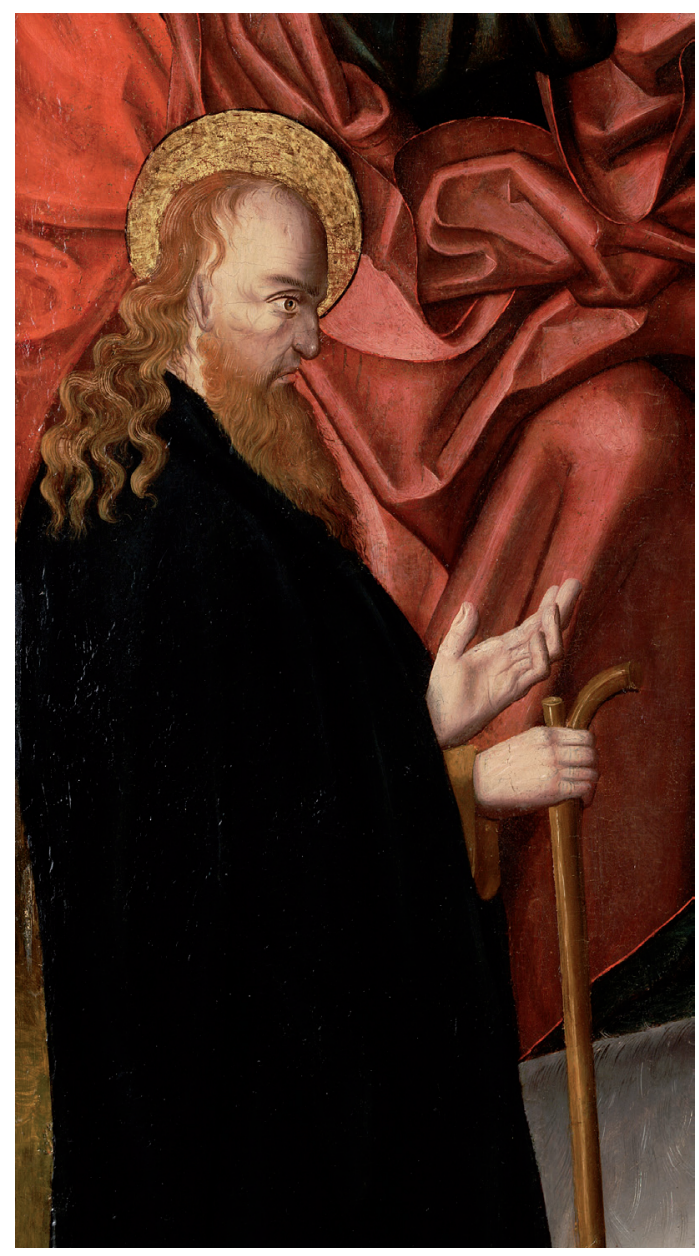

Fig. 6. Atribuido a Maestro Bartolomé. Entrada de Jesús en Jerusalén (detalle), c. 1480-1488. Tucson (Arizona): University of Arizona Art Museum. initio mundi (Nuremberg, 1493) de Hartmann Schedel $^{48}$. Barbara Anderson ha demostrado que Bartolomé usó diversas estampas del $\mathrm{Li}$ ber chronicarum en el retablo de Ciudad Rodrigo $^{49}$. Es curioso el modo en que se aplica el dorado en los celajes de algunas escenas, ya que no ocupa toda la superficie de los mismos, como si el oro se hubiera añadido en un momento posterior.

En la tabla del Martirio de San $\operatorname{Marcos}^{50}$ el estilo se ha empobrecido y simplificado debido a la participación del pintor cercano al Maestro

${ }^{48}$ Los tocados de los personajes de este incunable son muy repetitivos, pero los de los folios XL y CC son parecidos a los de esta escena. Las planchas para los grabados de esta obra fueron realizadas hacia 1490 por el taller de Michael Wolgemut y de su hijastro Wilhelm Pleydenwurff en Nuremberg; el libro fue el mayor éxito editorial de Antonius Koberger. Sabemos que Bartolomé se inspiró en él para las escenas del Caos y de la Creación de Eva del retablo de Ciudad Rodrigo y también lo usó en Trujillo. Anderson, 2008: 86-88; Sanz Fernández, 2009: 167. Se puede ver la versión digital en la web de la Biblioteca Digital Mundial: Liber chronicarum cum figuris ab initio mundi <www.wdl.org/es/item/4108/> [consultado el 21-XI-2019].

${ }^{49}$ La utilización de este libro ya fue señalada en: Yarza Luaces, 2006: 24. Anderson, 2008: 88-97. El uso más evidente e interesante del Liber chronicarum por parte de Bartolomé fue la célebre tabla del Caos. Hay un problema de fechas, todavía no resuelto, que impide dar una clara explicación al hecho de que se utilice un grabado publicado en 1493 en un retablo terminado en 1488.

${ }^{50}$ Réau, 1997: tomo 2, vol. 4, 324-26. 


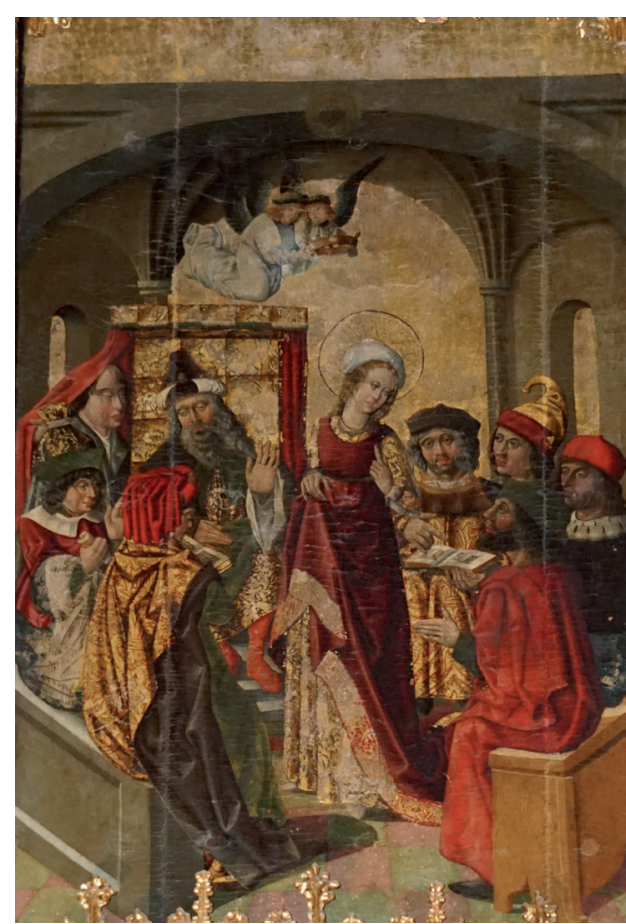

Fig. 7. Atribuido a Maestro Bartolomé y colaboradores. Disputa de Santa Catalina, c. 15001504. Catedral de Sigüenza (Guadalajara): Capilla de San Marcos.

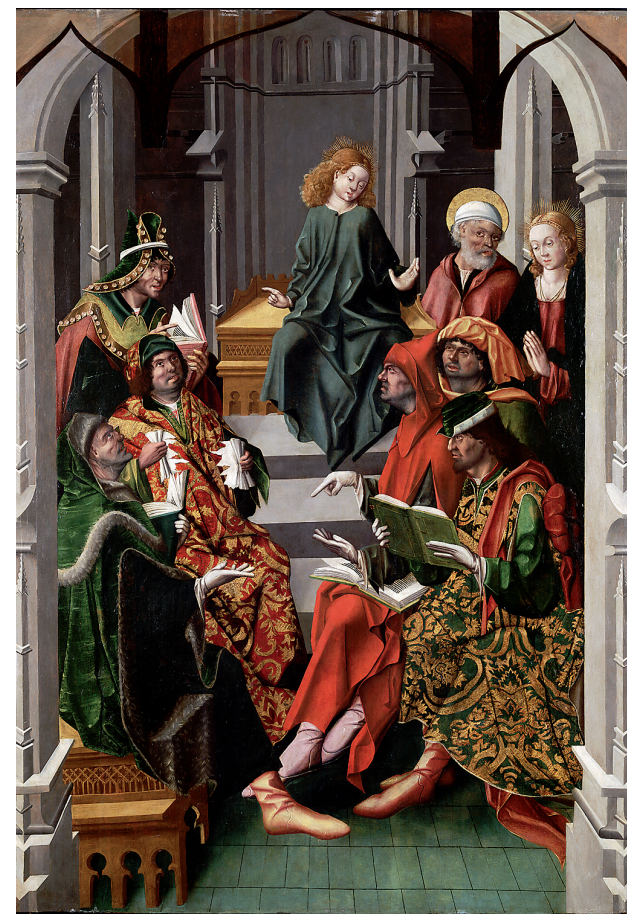

Fig. 9. Atribuido a Maestro Bartolomé. Jesús entre los doctores del Templo, c. 1480-1488. Tucson (Arizona): University of Arizona Art Museum.

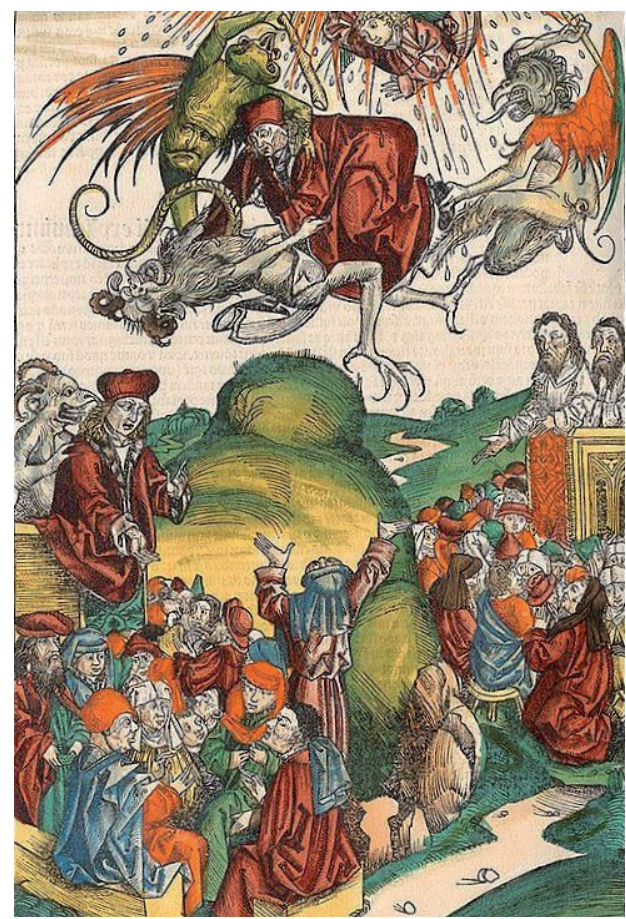

Fig. 8. Michael Wolgemut o Wilhelm Pleydenwurff. Anticristo, c. 1491-1493. En: Hartmann Schedel, Liber chronicarum cum figuris ab initio mundi (Nuremberg, 1493).

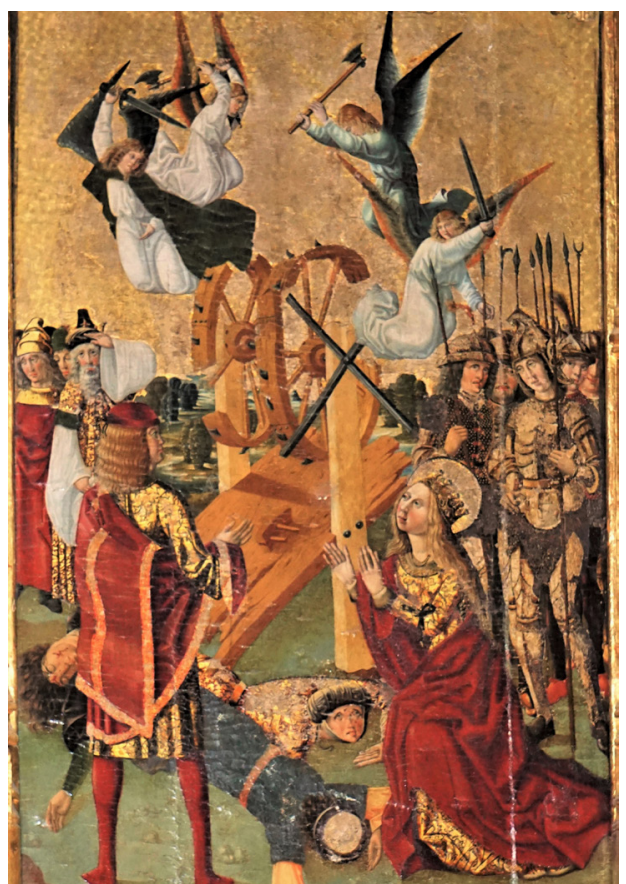

Fig. 10. Atribuido a Maestro Bartolomé y colaboradores. Tormento de las ruedas de Santa Catalina, c. 1500-1504. Catedral de Sigüenza

(Guadalajara): Capilla de San Marcos. 
de Sinovas, que reduce el número de figuras y el detallismo de arquitecturas, vestimentas y paisaje. La composición general y los sayones recuerdan a obras realizadas por el taller de Fernando Gallego. No obstante, la arquitectura del fondo está relacionada con la citada Entrada en Jerusalén del retablo de Ciudad Rodrigo.

En la Disputa de Santa Catalina [fig. 7] el autor se sirvió de la xilografía del Anticristo [fig. 8] del mencionado Liber chronicarum (fol. 262), para las dos figuras masculinas del primer plano. También mantiene una composición semejante a la escena de Jesús entre los doctores del Templo del UAMA [fig. 9]. En este sentido, la escena compara visual y conceptualmente a Santa Catalina con Jesucristo, ya que en ambos casos existió una especie de torneo filosófico y por ello el artista usó el mismo esquema compositivo en el que el protagonista aparece como doctor en cátedra explicando la lección ${ }^{51}$. La estructura espacial y arquitectónica remite a otros modelos de Bartolomé y de Fernando Gallego, aunque los tipos humanos, las manos y los rostros de ojos saltones recuerdan al retablo de Palazuelos de Muñó (Burgos), y a otras obras atribuidas al Maestro de Sinovas ${ }^{52}$. Solo en el rostro del personaje barbado del fondo se aprecian ecos del Maestro Bartolomé.

El Tormento de las ruedas de Santa Catalina [fig. 10] es un tema recurrente dentro del taller de Fernando Gallego, en quien se inspira lejanamente. Cuatro ángeles descienden del cielo para quebrar los radios de las ruedas y detener el tormento. Los tipos humanos también se aproximan al Maestro de Sinovas, si bien hay que decir que es un panel difícil de atribuir.

En la Crucifixión [fig. 11], los dos personajes a caballo se inspiran en el grabado del Camino del Calvario [fig. 12] de Schongauer, ya utilizado por Bartolomé (Entrada de Cristo en Jerusalén, Camino del Calvario y Crucifixión del UAMA) ${ }^{53}$, lo que indica que Bartolomé admiraba al maestro de Colmar y muy especialmente este grabado ${ }^{54}$. Ni el paisaje, ni la ciudad de fondo remiten a obras conocidas de Bartolomé, lo que parece indicar que no sería él quien terminara esta tabla. Los personajes más próximos a su estilo son la figura femenina de blanco y la Magdalena arrodillada, con esa manera dura de marcar los rasgos de sus rostros de perfil, como en la Magdalena de la Cena en casa de Simón del retablo de Ciudad Rodrigo. En la dulzura sosegada de algunos rostros y en la anatomía de Cristo se aprecian influjos que podrían pertenecer al citado colaborador italianizante.

\section{Posibles causas de la presencia de Bartolomé en la diócesis de Sigüenza}

Destacaremos tres posibles razones de la llegada de Bartolomé a Sigüenza y Almazán. La primera y más probable es que llegara para pintar o intentar acceder al contrato del antiguo retablo mayor de la catedral de Sigüenza, igual que había colaborado en el de la catedral de Ciudad Rodrigo. Hay varias referencias que hacen indudable la existencia de este retablo mayor fechado en torno a 1488, durante el episcopado del cardenal Mendoza ${ }^{55}$. Una obra de tal magnitud pudo atraer a artistas como Hernando Rincón, Frutos Flores, el Maestro de los Luna y sobre todo a un

${ }^{51}$ Réau, 1997: tomo 2, vol. 3, 274. Señala el paralelismo evidente entre Santa Catalina e Hipatia de Alejandría. También destaca el patronazgo de la santa sobre teólogos, estudiantes, escolares y algunas universidades, como la de El Burgo de Osma. Yarza Luaces, 2006: 31-34.

52 Post, 1947: 612.

53 Dotseth, 2008: 132-133.

${ }^{54}$ Aunque es un detalle secundario, la figura femenina de perfil del fondo de la escena también se inspira en otro grabado de Schongauer, la Crucifixión de la Serie de la Pasión. Sobre el uso de sus estampas en Castilla y Aragón: Silva Maroto, 1988. Lacarra Ducay, 2017.

${ }_{55}$ Actas Capitulares, 29 diciembre 1613, ACS, Sigüenza, fol. 106: “Comisión a Pedro Pérez, Hernán Sánchez y Valladares. Este día se dio comisión a los ss. canónigos Pedro Pérez, Fernando Sánchez y Luis Valladares, obrero para que repartan el retablo viejo que se quitó del altar mayor a las iglesias que les pareciere”. Debo el conocimiento de este documento a la amabilidad de Juan Antonio Marco Martínez. Este retablo fue sustituido por la magnífica máquina de Giraldo de Merlo en 1611. Pérez Villamil, 1899: 93, 211. Reproduce la inscripción que recuerda que el cardenal Mendoza mandó realizar el retablo. Minguella y Arnedo, 1912: 190 y 192: señala que junto al retablo había un retrato del cardenal. 


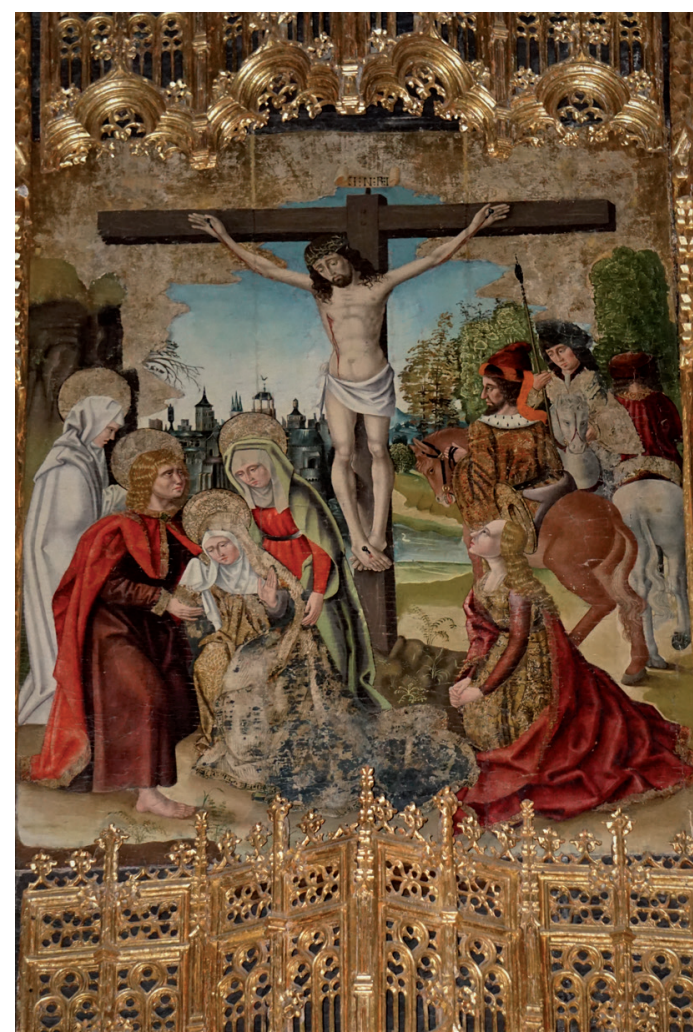

Fig. 11. Atribuido a Maestro Bartolomé y colaboradores. Crucifixión, c. 1500-1504. Catedral de Sigüenza (Guadalajara): Capilla de San Marcos. pintor con experiencia en este tipo de encargos como era Bartolomé ${ }^{56}$. Hay que recordar que el cardenal Mendoza retuvo el obispado de Sigüenza cuando fue elevado a arzobispo y que escultores como Rodrigo Alemán trabajaron en las catedrales de Ciudad Rodrigo, Sigüenza y Toledo. Lo cierto es que el cardenal Mendoza promovió obras de singular importancia en los presbiterios de las catedrales de sus sedes episcopales o arzobispales de Sevilla (1473-1482), Toledo (1482-1495) y Sigüenza (1468-1495) ${ }^{57}$, dejando una huella imborrable, incluyendo la de su propio sepulcro o la narración de la conquista de Granada en la sillería del coro de la catedral primada.

Una segunda posibilidad pudo ser la atracción de la nobleza de Almazán — una rama

${ }^{56}$ La existencia de este retablo mayor podría quizá explicar la llegada a Sigüenza de escultores como Sebastián de Almonacid, Peti Juan, Rodrigo Duque, Gaspar, Juan de Cercadillo, Alonso González o Francisco de Coca.

${ }^{57}$ Heim, 2003: 104-106: se dio cuenta de esta constante al estudiar el retablo mayor de la catedral de Toledo, cuyo proyecto y trazas atribuye a la iniciativa del cardenal Mendoza en 1488. Estas reformas en las capillas mayores y coros de las catedrales que dirigió también las promovió en los monasterios de San Francisco y San Bernardo, de los que fue protector en Guadalajara.

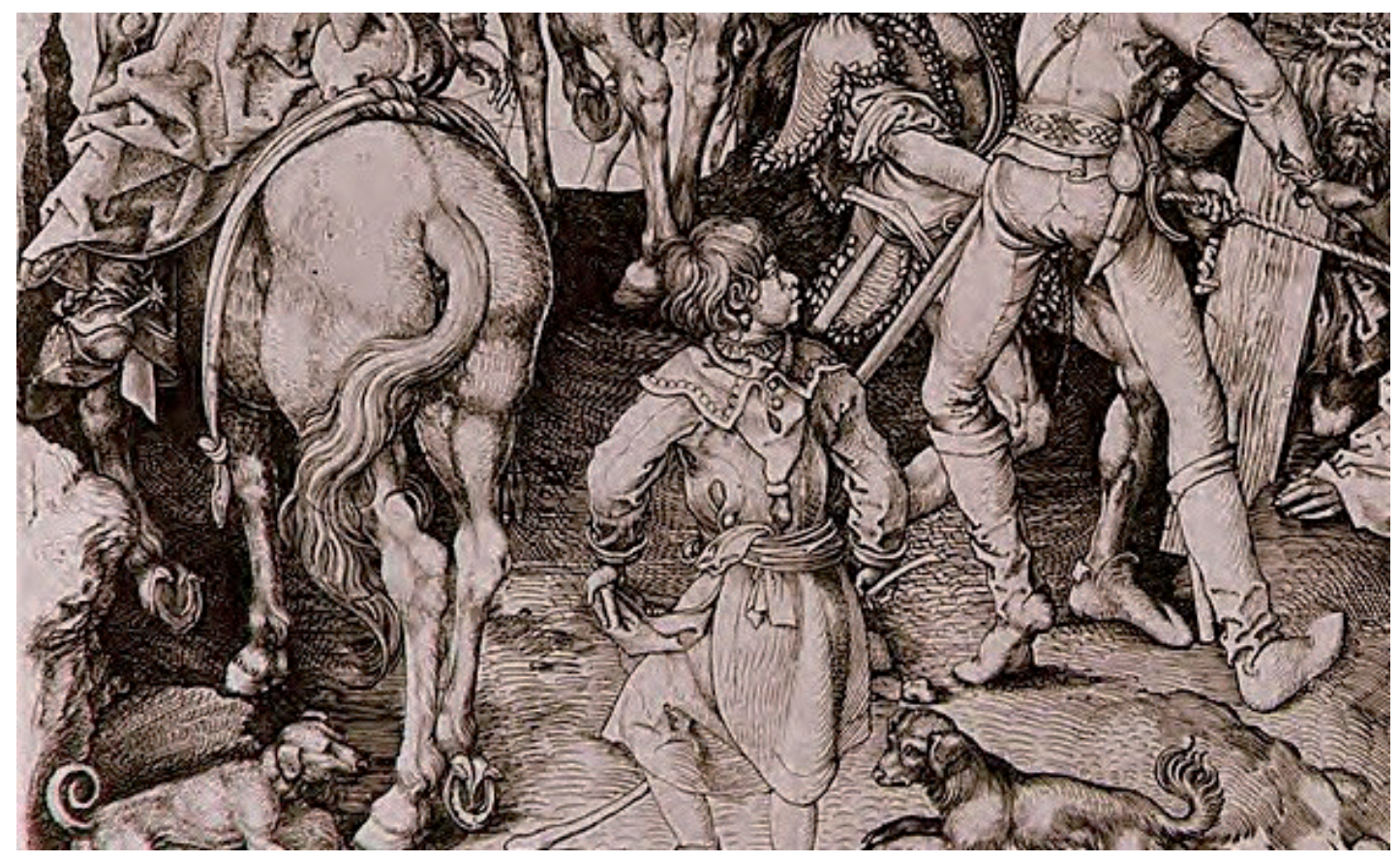

Fig. 12. Martin Schongauer (act. 1471-1491). Camino del Calvario (detalle). 
menor de los Mendoza-, cuya afición por la pintura flamenca se ha conocido gracias al reciente descubrimiento de dos magníficas tablas atribuidas a Hans Memling (Almazán, Ayuntamiento) ${ }^{58}$. En esos años se estaban realizando en Santa María del Campanario de Almazán retablos en los que trabajó el entallador Íñigo de Riaza ${ }^{59}$. Esta hipótesis explicaría su vecindad en Almazán.

En tercer lugar, no hay que descartar la posibilidad de que fuera llamado a Sigüenza por algún eclesiástico, quizá don Bernardino López de Carvajal, obispo de Sigüenza entre 1495 y 1512, pues existe un escudo de esta familia en la trasera del retablo de Santa María de Trujillo - Diego González de Carvajal era arcipreste de Trujillo cuando se realizó esta obra- ${ }^{60}$. Si aceptáramos esta hipótesis, habría que situar su llegada al obispado de Sigüenza después de 1495; y antes de ese año si nos decantáramos por la hipótesis del cardenal Mendoza. Cualquiera de las dos hipótesis es consistente con la ausencia de documentos que citen a Bartolomé en el área salmantina en esos años.

\section{Conclusión}

La atribución al Maestro Bartolomé que aquí proponemos abre nuevas perspectivas que pueden ayudarnos a ampliar el conocimiento que tenemos de este pintor y de la pintura hispanoflamenca en Castilla. Hasta ahora se le ubicaba en la década de 1480 colaborando con el taller de Fernando Gallego, y en la de 1490 independizándose de él. Si se demostrara cierta, ampliaría la trayectoria profesional del maestro hasta principios del siglo XVI y su labor se extendería hacia el este de Castilla. Desgraciadamente, su rastro se pierde nuevamente después de 1504, pues no se han encontrado huellas documentales en años posteriores. Si bien es cierto que la hipótesis que aquí defendemos no se apoya en ningún hecho incontrovertible, la coincidencia de los indicios documentales y de las semejanzas estilísticas de los dos santos titulares y de otros elementos del retablo con la obra conocida del Maestro Bartolomé, hacen que la hipótesis de la presencia de Bartolomé en Sigüenza y Almazán tenga visos de realidad.

Asimismo, este artículo contribuye a ampliar la compartimentada visión que a veces se tiene de la pintura hispanoflamenca castellana, pues los artistas viajaban y colaboraban entre sí con mayor asiduidad de lo que pensamos ${ }^{61}$.

\section{BIBLIOGRAFÍA}

Alba, Laura / García Maíquez, Jaime / Gayo, M. ${ }^{a}$ Dolores et al. (2014): "Las prácticas artísticas de los pintores «hispanoflamencos» en la Corona de Castilla en el siglo XV". En: Boletín del Museo del Prado, XXXII, 50, Madrid, pp. 122-147.

Anderson, Barbara C. (2008): "Maestro Bartolomé: the Artist in an Era of Humanism and Apocalypse". En: Dotseth, Amanda W. / Anderson, Barbara C. / Roglán, Mark A. (eds.): pp. 73-115.

Antelo, Tomás / Gabaldón, Araceli / Vega, Carmen (2008a): "Fernando Gallego en Trujillo: Estudios Físicos". En: Bienes culturales: revista del Instituto del Patrimonio Histórico Español, 8, Madrid: Instituto del Patrimonio Histórico Español, pp. 61-73.

Antelo, Tomás / Gabaldón, Araceli / Vega, Carmen (2008b): "El Retablo de Santa María La Mayor de Trujillo: dibujo subyacente". En: Bienes culturales: revista del Instituto del Patrimonio Histórico Español, 8, Madrid: Instituto del Patrimonio Histórico Español, pp. 75-88.

Azcárate Ristori, José María (1996): El arte gótico en España, Madrid, Cátedra.

\footnotetext{
${ }^{58}$ Muntada y Torrella, 2009: 430; 2010: 235-262. Quizás relacionadas con la estancia del Infante don Juan en Almazán.

${ }_{59}$ Existieron dos retablos más en Almazán a finales del siglo XV en Santa María de la Peña y en Nuestra Señora de los Milagros. Fernández Pardo, 2007: 189.

${ }^{60}$ La existencia de este escudo ha hecho pensar a Sanz Fernández que algún miembro de la familia Carvajal pudo haber encargado este retablo de Trujillo. El candidato mejor posicionado sería don Diego González de Carvajal, que fue rector de la Universidad de Salamanca en 1481. Sanz Fernández, 2009: 50-51 y 105.

${ }^{61}$ Silva Maroto, 2001: 91-112. Fiz Fuertes, 2012: 245. Aunque bastante posterior, es muy esclarecedor el estudio de Luis Vasallo Toranzo (2012) sobre la etapa castellana de Juan de Anchieta.
} 
Barry, Claire (2008): "The Making of the Ciudad Rodrigo Altarpiece". En: Dotseth, Amanda W. / Anderson, Barbara C. / Roglán, Mark A. (eds.): Fernando Gallego and his Workshop. The Altarpiece from Ciudad Rodrigo, London: Medows Museum / UAMA, pp. 147-226.

Camón Aznar, José (1978): Pintura medieval española. Summa Artis, vol. 22, Madrid: Espasa-Calpe (3a ed.).

Collar de Cáceres, Fernando (1989): Pintura en la antigua Diócesis de Segovia (1500-1630), Segovia: Diputación Provincial de Segovia.

Cómez Ramos, Rafael (2005): “Alemanes hispanizados o hispanos conversos. Una aproximación a la criptohistoria del arte español”. En: Piñero Ramírez, Pedro M. (coord.): Dejar hablar a los textos: Homenaje a Francisco Márquez Villanueva, vol. 2, Sevilla: Universidad de Sevilla, pp. 707-724.

Dotseth, Amanda W. / Anderson, Barbara C. / Roglán, Mark A. (2008.): Fernando Gallego and his Workshop. The Altarpiece from Ciudad Rodrigo, London: Medows Museum / UAMA.

Dotseth, Amanda W. (2008): "Maestro Bartolomé's Use of Prints in the Altarpiece of Ciudad Rodrigo". En: Dotseth, Amanda W. / Anderson, Barbara C. / Roglán, Mark A. (eds.): Fernando Gallego and his Workshop. The Altarpiece from Ciudad Rodrigo, London: Medows Museum / UAMA, pp. 117-143.

Federico, Aurelio de (1954): La catedral de Sigüenza, Madrid: Plus Ultra.

Fernández Pardo, Francisco (2007): Dispersión y destrucción del patrimonio artístico español. Desde comienzos del siglo hasta la Guerra Civil. 1900-1936, vol. IV, Madrid: Fundación Universitaria Española.

Fiz Fuertes, Irune (2010): "Aportaciones a la pintura salmantina de la primera mitad del siglo XVI". En: BSAA arte, LXXVI, Valladolid, pp. 91-102.

Fiz Fuertes, Irune (2012): "Les échanges entre la France et la Castille dans la peintre des XVe et XVI s.". En: Lugand, Julien (ed.): Les échanges artistiques entre la France et l'Espagne (XV'-fin XIXe siécles), Perpiñán, pp. 238-246.

Fiz Fuertes, Irune (2013): “Gil de Encinas y Bartolomé de Santa Cruz en el retablo de Horcajo de las Torres (Ávila) y su relación con el taller del Maestro de Astorga". En: BSAA arte, LXXIX, Valladolid, pp. 59-68.

Fiz Fuertes, Irune (2014): "Pintura hispanoflamenca y protorrenacentista en Valladolid". En: Wattemberg García, Eloísa (coord.), VII Curso Conocer Valladolid. VII Curso de patrimonio cultural, Valladolid: Ayuntamiento de Valladolid, pp. 157-171.

Fiz Fuertes, Irune (2015): "Pintura del primer tercio del siglo XVI en la antigua diócesis de Zamora". En: Hernández, José Luis (coord.): Sic vos non vobis. Colección de estudios en honor a Florián Ferrero, Zamora: Ministerio de Educación, Cultura y Deporte, pp. 407-439.

Fiz Fuertes, Irune (2018): "Los talleres pictóricos zamoranos en el siglo XVI: aprendices, oficiales y mujeres". En: Anuario del Instituto de Estudios Zamoranos Florián de Ocampo, 33, Zamora: Subdirección General de los Archivos Estatales, pp. 537-556.

García Sebastián, José Luis (1979): Fernando Gallego y su taller en Salamanca, Salamanca: Caja de Ahorros y M. P. de Salamanca.

Gaya Nuño, Juan Antonio (1958): Fernando Gallego, Madrid: CSIC.

Gómez, Marisa / Jover de Celis, Maite (2008): "Fernando Gallego en Trujillo: Estudios Químicos”, En: Bienes culturales: revista del Instituto del Patrimonio Histórico Español, 8, Madrid: Instituto del Patrimonio Histórico Español, pp. 49-60.

Gómez Espinosa, Teresa (2001): "Policromía del gótico final: retablo mayor de la catedral de Toledo y obras burgalesas de Gil de Siloe". En: Actas del Congreso Internacional sobre Gil Siloé y la escultura de su época, Burgos: Institución Fernán González / Academia Burgense de Historia y Bellas Artes, pp. 573-582.

Gómez Moreno, Manuel (1929): El arte en España. Guía del Museo del Palacio Nacional. Exposición Internacional de Barcelona, cat. exp. Barcelona: Palacio Nacional ( $3^{\mathrm{a}}$ ed.).

Gudiol Ricart, José (1955): Pintura Gótica. Ars Hispaniae. Historia Universal del Arte Hispánico, vol. IX, Madrid: Plus Ultra.

Heim, Dorothee (2003): "Entre Mendoza y Cisneros: la gestación del retablo mayor de la catedral de Toledo". En: Anales Toledanos, 39, Toledo, pp. 103-116.

Ibáñez Fernández, Javier (2018): “Bartolomé de Cárdenas, alias Bermejo, en Aragón. Una nueva perspectiva”. En: cat. exp. Bartolomé Bermejo, Madrid: Museo Nacional del Prado, pp. 85-103.

Lacarra Ducay, M. ${ }^{a}$ del Carmen (2017): "Influencia de Martín Schongauer en la pintura gótica aragonesa, nuevas reflexiones". En: Artigrama, 32, Zaragoza, pp. 41-70.

Marco Martínez, Juan Antonio (1997): El retablo barroco en el antiguo obispado de Sigüenza, Guadalajara: Diputación de Guadalajara.

Marías Franco, Fernando (2016): “Sobre los problemas de los artistas conversos en los Siglos de Oro". En: Franco Llopis, Borja / Pomara Saverino, Bruno / Lomas Cortés, Manuel / Ruiz Bejarano, Bárbara (eds.), Identidades cuestionadas. Coexistencia y conflictos interreligiosos en el Mediterráneo (ss. XIV-XVIII), Valencia: Universitat de Valéncia, pp. 425-447.

Marqués de Saltillo (1948): Artistas y artifices sorianos de los siglos XVI y XVII (1509-1699), Madrid: Imprenta y Editorial Maestre.

Mateo Gómez, Isabel (2002): "Bartolomé de Castro: formación y estilo”. En: Boletín del Seminario de Estudios de Arte y Arqueología, 68, Valladolid, pp. 199-224.

Minguella y Arnedo, Toribio (1912): Historia de la Diócesis de Sigüenza y de sus obispos, vol. 2, Madrid: Revista de Archivos, Bibliotecas y Museos (3 vols.). 
Muntada y Torrella, Anna (2009): “Santa Isabel de Hungría. San Francisco de Asís. San Bernardino de Siena. San Pedro”. En: Las Edades del Hombre. Paisaje Interior, cat. exp. Soria: Junta de Castilla y León, ficha n. ${ }^{\circ} 113$, pp. 430-438.

Muntada y Torrella, Anna (2010): "Las ignotas tablas de Hans Memling en Almazán". En: Casa Hernando, Mariano / Bango Torviso, Isidro G. (eds.): Jornadas de estudio y difusión del Patrimonio, Soria: Diputación de Soria, pp. 235262.

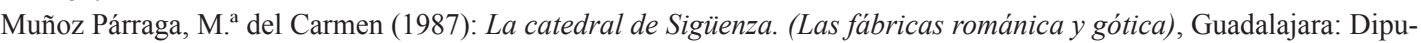
tación de Guadalajara / Cabildo de la S.I.C. de Sigüenza.

Olea Álvarez, Pedro A. (2016): Noticias insólitas del antiguo obispado de Sigüenza, Orduña (Vizcaya).

Peces Rata, Felipe (1997): "El retablo de la capilla de San Marcos y Santa Catalina”. En: Ábside, 27, Sigüenza, pp. 13-16.

Pérez Sánchez, Alfonso E. (1996): "Escuela española". En: Bettagno, Alessandro / Brown, Christopher / Calvo Serraller, Francisco (eds.): El Museo del Prado, Madrid, Fons-Mercator-Paribas / Fundación Amigos del Museo del Prado, pp. 15-189.

Pérez Sedano, Francisco (1914): Datos documentales inéditos para la historia del arte español. I. Notas del Archivo de la Catedral de Toledo, redactadas sistemáticamente, en el siglo XVIII, por el canónigo obrero don Francisco Pérez Sedano, Madrid: Centro de Estudios Históricos.

Pérez Villamil, Manuel (1899): Estudios de historia del arte. La catedral de Sigüenza erigida en el siglo XII. Madrid: Ed. Herres.

Post, Chandler Rathfon (1933): A History of Spanish Painting, IV, part 2, Cambridge (Massachussets): Harvard University Press.

Post, Chandler Rathfon (1947): A History of Spanish Painting, IX, part 2, Cambridge (Massachussets): Harvard University Press.

Quinn, Robert M. (1961): Fernando Gallego and the Retablo of Ciudad Rodrigo, Tucson (Arizona): Arizona University Press.

Ramos Gómez, F. Javier (1988): La pintura en Guadalajara y su jurisdicción (1500-1580), Guadalajara: Diputación de Guadalajara.

Ramos Gómez, F. Javier (2004): Juan Soreda y la pintura del siglo XVI en el antiguo obispado de Sigüenza, Guadalajara: Diputación de Guadalajara.

Ramos Rubio, José Antonio (2009): Inventario de pintura medieval en la Diócesis de Plasencia, Cáceres: Diputación Provincial de Cáceres.

Réau, Louis (1997): Iconografía del arte cristiano. Iconografía de los santos, tomo 2, Barcelona: Ed. Serbal (2 vols). [1. ${ }^{\circ}$ ed. 1957].

Redondo Cantera, M. ${ }^{a}$ José (2002): "Noticias sobre Alejo de Encinas y otros pintores activos en Salamanca durante la primera mitad del siglo XVI": En: Salamanca. Revista de Estudios, 48, Salamanca, pp. 175-186.

Redondo Cantera, M. José (2004): "Noticias sobre pintores contemporáneos de Pedro Berruguete en Valladolid": En Actas del Simposium Internacional Pedro Berruguete y su entorno, Palencia, Diputación de Palencia, pp. 371-382.

Romero Medina, Raúl (2009): "El taller de entalladores alcarreños de Lorenzo Vázquez y el retablo de la iglesia de Santa María de Medinaceli”: En: Boletín del Museo e Instituto Camón Aznar, 103, Zaragoza, pp. 35-62.

Sanz Fernández, Francisco (2009): Fernando Gallego y su Taller en el Altar Mayor de Santa María de Trujillo (Cáceres) Ca. 1490, Guadalajara, Barrantes-Cervantes Ed.

Serra, Amadeo (2010): "Modos de producción de retablos en la pintura gótica hispana. Las fuentes documentales y su interpretación”. En: La pintura europea sobre tabla. Siglos XV, XVI y XVII, Madrid, Instituto del Patrimonio Histórico Español, pp. 13-19.

Silva Maroto, M. ${ }^{a}$ Pilar (1988): "Influencia de los grabados nórdicos en la pintura hispanoflamenca". En: Archivo Español de Arte, 61, 243, Madrid, CSIC, pp. 271-289.

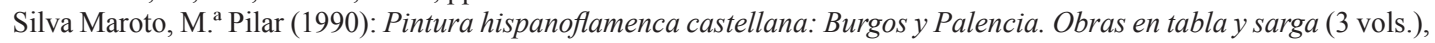
Valladolid, Junta de Catilla y León.

Silva Maroto, M. a Pilar (1992): "En torno a Bartolomé de Castro". En: Homenaje al profesor Hernández Perera, Madrid, Universidad Complutense de Madrid, pp. 437-452.

Silva Maroto, M. ${ }^{a}$ Pilar (1996): "En torno a la pintura del primer tercio del siglo XVI en Palencia: el Maestro de la Calzada". En: Anales de Historia del Arte, 6, Madrid, Universidad Complutense de Madrid, pp. 163-179.

Silva Maroto, M. ${ }^{a}$ Pilar (2004): Fernando Gallego, Salamanca, Caja Duero.

Tormo y Monzó, Elías (sin fecha): Sigüenza, Madrid, Patronato Nacional de Turismo.

Torné Poyatos, Angelina (1987): La pintura gótica española en el Museo del Prado. Tesis doctoral inédita, Madrid: Universidad Complutense de Madrid.

Vasallo Toranzo, Luis (2012): Juan de Anchieta, aprendiz y oficial de talla en Castilla 1551-1571, Valladolid: Universidad de Valladolid.

Vicente Baz, Raúl (2008), Los Libros de Actas Capitulares de la catedral de Salamanca. (1298-1489). Colección Instrumentos del Archivo Catedral 2, Salamanca: Publicaciones del Archivo Catedral de Salamanca.

Vicente Baz, Raúl (2016), Los Libros de Actas Capitulares de la catedral de Salamanca. II (1489-1506). Colección Instrumentos del Archivo Catedral 5, Salamanca: Publicaciones del Archivo Catedral de Salamanca.

Yáñez Neira, Damián M. (1986): “Fray Ignacio de Collantes”. En: Wad-al-Hayara, 13, Guadalajara, pp. 385-400.

Yarza Luaces, Joaquín (2001): "El retablo mayor de la cartuja de Miraflores". En: Actas del Congreso Internacional sobre Gil de Siloé, Burgos: Institución Fernán González / Academia Burgense de Historia y Bellas Artes, pp. 207-238. 
Yarza Luaces, Joaquín (2006): "El retablo mayor de la catedral de Ciudad Rodrigo de Fernando Gallego". En: Azofra, Eduardo (ed.), La catedral de Ciudad Rodrigo. Visiones y revisiones, Salamanca: Diputación de Salamanca, pp. 1560 .

Yela Utrilla, Juan Francisco (1923): “Documentos para la historia del cabildo seguntino. IV”. En: Boletín de la Real Academia de la Historia, 82, Madrid, pp. 372-387.

Zarco del Valle, Manuel R. (1916): Datos documentales para la historia del arte español. II. Documentos de la catedral de Toledo: colección formada en los años 1869-74 y donada al centro en 1914 por Manuel R. Zarco del Valle, Madrid: Centro de Estudios Históricos.

Fecha de recepción: 10-VIII-2020

Fecha de aceptación: 26-XI-2020 